\title{
La hermenéutica literaria de Michel Foucault*
}

\section{Literary Hermeneutics of Michel Foucault}

\author{
Azucena González Blanco \\ Universidad de Granada \\ azucena@ugr.es \\ ORCID iD: https://orcid.org/0000-0002-0716-4214
}

\section{RESUMEN}

El objetivo de este estudio es analizar los rasgos de la hermenéutica literaria de Michel Foucault en los textos sobre literatura en el período que llega hasta 1970. Este trabajo muestra cómo su hermenéutica literaria comparte una misma raíz con su arqueología. Para ello, primero, se va a partir de una aproximación al privilegio otorgado a la lectura en el proyecto metodológico foucaultiano, para después analizar particularmente las repercusiones de este proyecto metodológico en el ámbito literario y poder describir así la especificidad de su hermenéutica literaria. La hermenéutica literaria de Foucault no deja de estar vinculada al análisis del texto. Por este motivo, los rasgos fundamentales de la hermenéutica ontológica de la literatura foucaultiana van a ser descritos en relación a su obra Raymond Roussel.

Palabras Clave: hermenéutica; M. Foucault; literatura; arqueología; ontología.

\begin{abstract}
The aim of this study is to analyze the features of literary hermeneutics of Michel Foucault in his texts on literature covering until 1970. Our proposal shows how his literary hermeneutics shares a root with its archaeological hermeneutics. To do this, first, it goes from an approach to privileging of reading Foucault's methodological project, then particularly analyzes the impact of this methodological project in the literary field and describes the specificity of his literary hermeneutics. Foucault literary hermeneutics is always linked to the analysis of the text. For this reason, the fundamental features of ontological hermeneutics of literature Foucaultian will be described in relation to his work Raymond Roussel.
\end{abstract}

Key words: Hermeneutics; M. Foucault; Literature; Archaeology; Ontology.

${ }^{*}$ Este trabajo se realiza en el marco del proyecto de investigación: «Procesos de subjetivación: biopolítica y política de la literatura. La herencia del último Foucault» (FFI201564217-P), y en colaboración con el proyecto «Actualidad de la hermenéutica. Nuevas tendencias y autores», que dirige Sultana Wahnón Bensusan. 


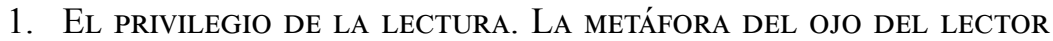

Según Cristina de Peretti en «Foucault: The Twofold Games of Language» (1994), «la arqueología está resueltamente basada sobre el privilegio de la lectura» (Peretti 1994: 35). Se podría considerar, in extremis, que el rasgo que recorre cada una de sus metodologías, tanto la genealogía como la arqueología, están basadas en el acto de la lectura. Pero la lectura no es, como expone Foucault en L'ordre du discourse (1971), un modo de aprehender el texto en una «verdadera, correcta y única lectura». Al contrario, el concepto de hermenéutica - como lo expone claramente en «Nietzsche, Marx, Freud» ${ }^{1}$ (Foucault 2001: 592-608) — es sinónimo de texto históricamente plurisignificativo.

Al mismo tiempo, como el marco dentro del cuadro, la lectura en Foucault se refiere al acto mismo en el que la vista se enfrenta a la materialidad de las letras del volumen. De ahí la caracterización de nuestra cultura como Biblioteca o el interés de Foucault por el archivo. Para el autor, la historiografía no es un capítulo objetivo del conocimiento, sino que en su enfrentamiento con la palabra escrita de los textos, con la lectura, el lenguaje desborda cualquier posibilidad de representación transparente de la historia. Esta misma materialidad es la que permite a Foucault una reconsideración del concepto de historia en relación con el concepto de escritura y, en particular, con el de archivo. Modelo espacial de la historia en contraposición al temporal, como desarrollo lineal que permite la superación de estratos. En la arqueología, por tanto, se atiende a la materialidad de la historia a través de la materialidad del archivo, como ya lo hizo antes en su «arqueología de la modernidad» Walter Benjamin ${ }^{2}$, para quien tampoco hay utopía de futuro, sino que cada presente disuelve el pasado y, a la vez, es capaz de renovarlo. En este ponerse frente a la escritura, la metáfora del ojo del lector será esencial en el pensamiento de Foucault que, en su debate con la dialéctica, enfrenta a la percepción abstracta de la mente, supuestamente superadora del ojo y del oído según Hegel (2004) —y aquí Hegel utiliza el ojo en un sentido no figurado-, la imposibilidad de saltar el acto mismo de la lectura. Y el desarrollo de la hermenéutica está vinculado a esta metáfora del ojo del lector en Foucault. Metáfora que, como pone de relieve Martin Jay en su trabajo, Ojos abatidos. La denigración de la visión en el pensamiento francés del siglo XX (2008), goza de una larga tradición y sucesivas transformaciones. Martin Jay (2008: 34) expone la existencia de un gran número de metáforas de la visión que hablarían de una profunda relación

1 Todos los textos que Foucault dedica a la literatura y que van a ser citados aquí han sido publicados en Dits et écrits (I y II) con excepción de «Langage et littérature» (1964) que se publicaba por primera vez en francés en la antología de textos sobre literatura $L a$ grande étrangère. À propos de littérature (2013).

${ }^{2}$ La imagen utilizada por Benjamin (1923) es la de las «ruinas del pasado» en «La tarea del traductor». 
entre la percepción y el lenguaje mismo: según él, la epistemología de esta metáfora se aproxima a la «representatividad» del lenguaje.

Esta metáfora, recurrente en la obra de Foucault, se contextualizaría por tanto en el panorama de la filosofía que le era contemporánea pero también como crítica del privilegio otorgado al órgano del ojo en la Fenomenología, fundamentalmente de Merleau-Ponty (Phénomenólogie de la perception, 1945; Le visible et l'invisible, 1964; Le primat de la perception et ses conséquences philosophiques, 1966). Foucault denuncia de este modo el etnocentrismo presente en este privilegio, que imposibilita pensar lo Otro. Así lo ha destacado Cristina Micieli en Foucault y la fenomenología (2003), al hablar de:

Su intento de escapar de la monarquía del doble empírico-trascendental, dado que el paradigma antropológico es, en el modo histórico del análisis del pensamiento, la forma misma de un tipo de racionalidad cómplice con el etnocentrismo, esto es, con la imposibilidad misma de pensar lo Otro (Micieli 2003: 29).

Como precedente de este uso de la imagen del ojo, también Walter Benjamin la había desarrollado en relación con la materialidad del discurso histórico. Como señala Sagnol en «La méthode archéologique de Walter Benjamin» (1983), las reflexiones sobre la Filosofía de la Historia, que representan el armazón teórico de su estudio sobre los Pasajes, parten de una serie de críticas dirigidas principalmente a la ideología del progreso. Tanto Benjamin como Foucault compartirían la herencia de Nietzsche que critica el concepto de historia teleológica porque olvida los pequeños eventos. Foucault y Benjamin habrían retomado la metáfora del ojo nietzscheana - de origen leibniziano, como señala Sarah Kofman en Nietzsche et la métaphore-, que es la del perspectivismo. Y con ello habrían afrontado la historia como «historia efectiva» y no como continuum. De este modo, afirma Sagnol:

Il n'est pas certainement pas exagéré du dire que l'archéologie de Foucault est fille du matérialisme historique et de la généalogie nietzschéenne, et qu'en cela elle n'est pas totalement étrangère à l'archéologie de, qui, s'il proclame haut et fort le matérialisme historique, n'est pas moins également influencé par Nietzsche (Sagnol 1983: 143-165).

Así, estos autores se enfrentarían a la tendencia clásica que desde Platón considera al ojo el órgano privilegiado para representar la visión espiritual («camino natural hacia el alma»), la intuición, dada su situación elevada y alejada del contacto con lo material, frente al olfato y el gusto, según explica Jay. Con ello, Foucault estaría deconstruyendo el símbolo del ojo, al hacerlo imprescindible en la percepción de la materia a través del acto de lectura, frente a la transparencia de la imagen que devuelve el ojo del que percibe. El ojo ya no mira una «realidad objetiva», ya no percibe fielmente lo que sea la realidad: el ojo es el ojo del lector, el ojo que atiende a los signos de la escri- 
tura. En Raymond Roussel, la lectura abre la posibilidad de ver pero no es lo visto mismo, como la lente de la Vue, o como los dobles que en la obra de Roussel definitivamente esconden más que reproducen - "visibilidad irradiante en la cual nada es visible» (Foucault 1963: 67) - es el exceso que no permite ver. O también, como sucede en la obra que Foucault dedica a René Magritte, Ceci n'est pas une pipe (1973), la imposibilidad de reconciliar imagen y palabras, deshace la ilusión clásica de la continuidad entre lo visto y lo dicho.

Por otra parte, la nueva crítica sería el ojo que permite, a través de imágenes, relacionar el pensamiento con lo visible. Así lo expone Foucault en «Le Mallarmé de Jean-Pierre Richard $»^{3}$ (1964), donde asegura que la lectura del texto literario da a ver en la imagen un «pensamiento poético», y no un referente. Por otra parte, esta metáfora es una clara referencia a Georges Bataille, quien, en La historia del ojo (1928), descompone la oposición entre lo bajo y lo alto, al considerar que el ojo es siempre y al mismo tiempo un sexo y un ojo, sin que estos opuestos puedan ser recogidos en un tercer término. Foucault retoma también esta metáfora como metáfora de la transgresión. En «Préface à la transgression» (1963), para Foucault la metáfora del ojo es la transgresión del sí mismo, el «ojo vuelto»:

Son globe a l'expansion d'un germe merveilleux -comme celle d'un oeuf, qui éclaterait sur lui-même vers ce centre de nuit et d'extrême lumière qu'il est et qu'il vient de cesser d'être. Il est la figure de l'être qui n'est que la transgression de sa propre limite (Foucault 2001: 272-273).

La metáfora del ojo ciego, volteado, «el ojo más cerrado y a la vez más abierto», continúa el juego del límite y del ser en la obra de Bataille (ibíd.: 273). Ojo volteado que es más que una metáfora en la que Bataille recoge lo que ha denominado experiencia interior, extremo de lo posible, operación cómica o sencillamente meditación (L'Expérience de l'intérieur, 1943); del que no es una metáfora la mirada clara de Descartes o esa agudeza de espíritu que llama acies mentis. Según Foucault, es precisamente esta metáfora la que marca el límite del pensamiento de Bataille:

À vrai dire, l'œil révulsé, chez Bataille, ne signifie rien dans son langage, pour la seule raison qu'il en marque la limite. Il indique le moment où le langage arrivé à ses confins fait irruption hors de lui-même (...) les yeux bouleversés de

3 Texto especialmente interesante por la estructura de mise en abyme: sería lo que podría denominarse un texto no ya de lenguaje secundario, sino tercero, en tanto que es un lenguaje (Texto de Foucault), sobre lenguaje (texto de Jean-Pierre Richard) sobre lenguaje (textos de Mallarmé) «Le Mallarmé de Jean-Pierre Richard» es una reseña de la obra de J.-P. Richard, L'Univers imaginaire de Mallarmé (1962). Reseña en la que Foucault realiza una defensa de la nouvelle critique y, en particular, de la lectura realizada por Jean-Pierre Richard sobre la obra de Mallarmé, frente a las lecturas que se habían realizado desde el psicoanálisis, principalmente. 
l'extase, l'horreur muette et exorbitée du sacrifice, et demeure ainsi à la limite de ce vide (...) L'œil énucléé ou renversé, c'est l'espace du langage philosophique $\mathrm{du}$ Bataille, le vide où il s'épanche et se perd mais ne cesse de parler — un peu comme l'œil intérieur, diaphane et illuminé des mystiques ou des spirituels marque le point où le langage secret de l'oraison se fixe et s'étrangle en une communication merveilleuse qui le fait taire. De même, mais sur un mode inversé, l'œil de Bataille dessine l'espace d'appartenance du langage et de la mort, là où le langage découvre son être dans le franchissement de ses limites: la forme d'un langage non dialectique de la philosophie (Foucault 2001: 275).

Desde ahí es desde donde se observa el «ser del límite». Foucault desarrolla esta imagen en su propia obra, que reúne una de Leiris y la propia de Bataille: «Es en todo caso en la playa blanca de la arena (ojo gigantesco) donde Bataille ha realizado esta experiencia (...)» (ibíd.: 277). Según Arne Klawitter ${ }^{4}$, la función de esta metáfora cumple un papel fundamental en la hermenéutica ontológica de la literatura que Foucault propone. Para Klawitter, el ojo volteado es un «monumento lingüístico» autosuficiente, «un significante (Signifikat) hueco» con una doble función: referido al ser del lenguaje, al tiempo que significante absoluto por «remitir al lugar vacío del sujeto soberano» (Klawitter 2003: 131). Para indicar la función del ojo volteado, Foucault habría diferenciado, al menos implícitamente, entre ver (Sehen) y mirar (Blicken). Esta diferenciación la relaciona Klawitter con la distinción romántica de Abrams del espejo y la lámpara. En el primer caso, el ojo aparecería bien como espejo bien como lámpara. Como espejo, estaría referido a la función autorreflexiva (cuando se ve a sí mismo viendo); como lámpara, el ojo aparecería como el que recoge la luz del mundo y la convierte en una imagen individual y subjetiva. En contraposición al ver, Foucault caracterizaría, según Klawitter, el ojo que mira como una lámpara también, si bien ésta como lámpara de la noche «cuya luz extraña no alumbra al mundo, sino que demuestra su propio vacío» (Klawitter 2003: 130). El ojo del lector encontraría alternativamente la imagen del ojo que se observa a sí mismo leyendo y la lectura particular que sobre la escritura realiza.

Por otra parte, el concepto de lectura en Foucault va indisociablemente unido a otro igualmente determinante en su proyecto global. Se trata del concepto de experiencia. El sentido en que Foucault asume el término se clarifica cuando afirma en varias ocasiones que sus libros han de concebirse como «experiencias que impulsan al cambio». La experiencia, pues, como puesta a prueba de uno mismo, pero también como puesta a prueba del lector. Y es también desde aquí desde donde es posible vislumbrar una nueva consideración de la noción de lector, pues, como para Blanchot ${ }^{5}$, el lector es el que se rela-

${ }^{4}$ Todas las referencias de la obra de Arne Klawitter (2003) que aparecen en este trabajo son traducciones propias.

${ }^{5}$ En su novela Thomas l'obscur (Nouvelle Version. Gallimard, Paris, 1950), Blanchot desarrollaba la alegoría del lector como un nuevo tipo de lector que no impone su ser a lo 
ciona con la letra y es transformado por ella sin imponerse. Frente al autor que reconoce e impone la unidad de la obra, la figura del lector que diversifica y disemina las posibles lecturas, siempre múltiples. Y ello como negación del comienzo, esto es, como la imposibilidad de desvelar una identidad primera y de llegar a esa «verdad» velada por el tiempo.

Por otra parte, esta hermenéutica es también un modo de aproximarse a los textos, de enfrentarse a los textos directamente, como un «dar a ver» el texto y ha sido utilizada frecuentemente por Foucault tanto en sus análisis críticos sobre literatura, como en sus «descripciones» arqueológicas.

Esta hermenéutica atendería a la singularidad de los acontecimientos, como apertura de la posibilidad y tratamiento arqueológico y erudito de la materia. Pues esta hermenéutica genealógica es a los textos y los acontecimientos lo que la arqueología a los monumentos, es decir, atiende a su materialidad en contra del enfoque metafísico y, dado su trabajo sobre el acontecer, supera, así también, al Estructuralismo. Así lo explica el propio Foucault en «Nietzsche, Marx, Freud» (1964). Como los autores de la sospecha, Foucault cree que el lenguaje no dice exactamente lo que dice, el lenguaje rebasa la utilización que tradicionalmente se le ha dado, «no es ya la casa del sujeto». Esto es, las mismas palabras no serían sino interpretaciones. A todo lo largo de su historia, «antes de convertirse en signos, interpretan, y tienen significado finalmente porque interpretan», de modo que:

Il n'y a rien d'absolument premier à interpréter, car au fond, tout est déjà interprétation, chaque signe est en lui-même no pas la chose qui s'offre à l'interprétation, mais interprétation d'autres signes (Foucault 2001: 599).

En este sentido, cuestionaba Nietzsche en Sobre verdad y mentira en sentido extramoral, el concepto mismo de verdad:

¿Qué es entonces la verdad? Una hueste en movimiento de metáforas, metonimias, antropomorfismo, en resumidas cuentas, una suma de relaciones humanas que han sido realzadas, extrapoladas y adornadas retóricamente y que, después de un prolongado uso, un pueblo considera firmes, canónicas, vinculantes; las verdades son ilusiones de las que se ha olvidado que lo son (Nietzsche 1994: 6).

Esto es, la idea de que la interpretación precede al signo implica que las palabras son ya interpretaciones; no indican un significado, sino que imponen una interpretación. Por ello, dice Foucault, el valor decisivo de la hermenéutica moderna consiste en desvelar este hecho. La hermenéutica literaria está marcada, a su vez, por la naturaleza polisemántica de la literatura. La hermenéutica literaria sería entonces el análisis de la literatura como significante y significándose a sí misma. Y la literatura sería, en consecuencia:

leído, que no pretende en la lectura exponerse, sino que se deja transformar por el ser del lenguaje (González Blanco 2007). 
Polysémantique, mais sur un mode singulier, non comme on dit qu'un message peut avoir plusieurs significations et qu'il est ambigu, mais en réalité, la littérature est polysémantique, cela veut dire que, pour dire une seule chose ou peut-être pour ne rien dire du tout - car rien ne prouve que la littérature doit dire quelque chose la littérature est toujours obligée de parcourir un certain nombre de couches sémiologiques [...] C'est-à-dire que la littérature n'est pas autre chose que la reconfiguration, sous une forme verticale, de signes qui sont donnés dans la société, dans la culture, en couches séparées; c'est-à-dire que la littérature ne se constitue pas à partir du silence, la littérature, ce n'est pas l'ineffable d'un silence, la littérature, ce n'est pas l'effusion de ce qui ne peut pas se dire et qui ne se dira jamais. [La literatura es el murmullo incesante] (Foucault 2013: 128; Foucault 1996: 94').

\section{El ESTATUTO DE LA INTERPRETACIÓN COMO TEXTO SECUNDARIO}

Los análisis literarios de Foucault, como sus otros estudios, se desarrollan a partir de la práctica discursiva, incluso en sus textos más evidentemente teóricos, como «Langage et littérature» (1964). La hermenéutica de Foucault se aproximaría así al inmanentismo del new criticism, pero con la influencia del psicoanálisis, el estructuralismo y, sobre todo, de su arqueología.

Al igual que otros teóricos y críticos contemporáneos, vinculados a lo que se denominó nouvelle critique ${ }^{7}$ y al movimiento estructuralista ${ }^{8}$, Foucault se enfrenta así a la crítica tradicional, si bien en su caso este modo de lectura está basado, al mismo tiempo, en su concepto de lenguaje. Pues, si el lenguaje se define en su capacidad significante no sólo por su carácter referencial sino sobre todo por su carácter perlocutivo (en tanto que creativo)

${ }^{6}$ La edición francesa de la conferencia «Littérature et langage» (Facultés universitaires Saint-Louis, en Bruselas, 1964) se publicó en 2013, y es posterior a la traducción española de Ángel Gabilondo de 1996. Existen algunas diferencias entre ambas ediciones. En este caso, se ha completado la cita del texto francés con una frase que sólo aparece en la edición española y que aquí aparece entre corchetes y en español para distinguir ambas ediciones.

${ }^{7}$ Como ha indicado Manuel Asensi en su Historia de la teoría de la literatura, vol. II, «nouvelle critique» es una designación amplia y heterogénea en la que se engloban las nuevas tendencias teóricas y críticas que se desarrollan en Francia en particular, y en Europa en general, en los años sesenta, de las cuales algunas ya venían desarrollándose desde los años treinta: «Movimientos como el estructuralismo genético de filiación marxista (cuyo máximo representante es Lucien Goldmann), la psicocrítica (Charles Mauron), la tardía crítica de la conciencia (Jean-Pierre Richard, Jean Rousset), o la de la conciencia negativa (Maurice Blanchot), forman parte de la nouvelle critique, una clase de discurso teórico y crítico que llevó a cabo una renovación de los estudios literarios en Francia y en la Europa de aquellos años» (Asensi 2003: 341).

${ }^{8}$ Foucault realiza una defensa de estas «nuevas tendencias», defensa que se encuentra en diversos textos, entre los que destacan: «Le Mallarmé de J.P. Richard» (1964), «Langage et littérature» (1964), «Le Structuralisme et l'analyse littéraire», «Proposition de création d'une chaire intitulée Sémiologie littéraire» para Roland Barthes (1975). 
y por su capacidad de detenerse sobre sí mismo, de significarse a sí mismo, en su carácter ontológico (puesto que lúdico), ¿qué sucede con la crítica literaria que se había venido definiendo como un lenguaje secundario capaz de re-establecer el vínculo entre el texto y el autor, o entre el texto y el referente? Resulta obvio que el estatuto y naturaleza de este discurso va a ser redefinido.

En esta redefinición de la crítica y la hermenéutica del texto literario como texto secundario, Foucault se distancia de la radicalidad de algunas propuestas que le eran contemporáneas. En la conferencia pronunciada en 1970 en el Collège de France, L'ordre du discourse, con motivo de la sucesión de Jean Hippolite en la cátedra de historia de los sistemas de pensamiento, Michel Foucault especifica el estatuto que otorga al texto secundario o comentario. Al respecto de la hermenéutica como texto secundario, o "comentario», que es señalado como un procedimiento de control del discurso del que, no obstante, no se puede prescindir, dice Foucault:

Je suppose, mais sans en être très sûr, qu'il n'y a guère de société où n'existent des récits majeurs qu'on répète et qu'on fait varier; des formules, des textes, des ensembles ritualisés de discours qu'on récite, selon des circonstances bien déterminées; des choses dites une fois et que l'on conserve, parce qu'on y soupçonne quelque chose comme un secret ou richesse. Bref, on peut soupçonner qu'il y a, très régulièrement dans la sociétés, une sorte de dénivellation entre les discours: les discours qui «se disent» au fil des jours et des échanges, et qui passent avec l'acte même qui les a prononcés; et les discours qui sont à l'origine d'un certain nombre d'actes nouveaux de paroles qui les reprennent, les transforment ou parlent d'eux, bref, les discours qui, indéfiniment, par-delà leur formulation, sont dits, restent dits, et sont encore à dire. Nous les connaissons dans notre système de culture: ce sont les textes religieux ou juridiques, ce sont aussi ces texte curieux, quand on envisage leur statut, et qu'on appelle « littéraires »; dans une certaine mesure des textes scientifiques (Foucault 1971: 23-24).

Como se ve, no se trata aquí de la indistinción radical entre discurso primero y discurso secundario, que otros autores reivindicaron en estos años. Entre ellos, Roland Barthes quien afirmaba en Critique et vérité (1966): «Un mismo lenguaje tiende a circular por doquier en la literatura, y hasta detrás de sí mismo (...) no hay ya poetas, ni novelistas, no hay más que una escritura» (Barthes 1966: 47). Según Barthes, la definición misma de la objetividad que se demandaba a la crítica estaba sometida a una noción históricamente variable: la «exterioridad» — definida como razón, naturaleza, gusto, la vida del autor, las leyes del género o la historia - que habría modificado igualmente lo verosímil crítico. En este mismo sentido, la Deconstrucción, y principalmente Paul de Man, negaban también que existiera una diferencia radical entre lenguaje primero u original y lenguaje secundario.

La diferencia estriba en que, si bien para Foucault ambas categorías no son cerradas dada su historicidad, hay textos secundarios o comentarios que ocupan 
en ocasiones el lugar de los primeros, y otros primeros o creadores que desaparecen. No obstante, «la desaparición radical de este desnivel no puede ser nunca más que juego, utopía o angustia», dice Foucault; y se refiere a la ironía que contiene el Pierre Menard de Borges y a la angustia de Roussel. Angustia de ese enfermo de Janet para quien el menor enunciado era como una «palabra del Evangelio» que encerraba inagotables tesoros de sentidos y que merecían ser indefinidamente reconsiderados, reanudados, comentados: «cuando pienso», decía, «en la frase que va a irse hacia la eternidad y que quizá todavía no he comprendido completamente» (Foucault 1963: 27-28).

Así pues, como para Barthes, también para Foucault el estatuto de los textos varía según el momento histórico. La diferencia estriba en que para éste, no obstante, la distinción en sí misma no desaparece. Según Foucault, el texto primero es repetido de muchas formas. «Una sola y misma obra literaria puede dar lugar simultáneamente a tipos de discursos muy diferentes: la Odisea como primer texto es repetida, en la misma época, en la traducción de Bernard, en infinitas explicaciones de textos, en el Ulises de Joyce» (Foucault 1971: 28). La relación entre estos dos tipos de textos, por lo tanto, es abierta y «solidaria»:

Dans ce qu'on appelle globalement un commentaire, le décalage entre texte premier et texte second joue deux rôles qui sont solidaires. D'une part, il permet de construire (et indéfiniment) des discours nouveaux: le surplomb du texte premier, sa permanence, son statut de discours toujours réactualisable, le sens multiple ou caché dont il passe pour être détenteur, la réticence et la richesse essentielles qu'on lui prête, tout cela fonde une possibilité ouverte de parler. Mais, d'autre part, le commentaire n'a pour rôle, quelles que soient les techniques mises en œuvre, que de dire enfin ce qui était articulé silencieusement là-bas. Il doit, selon un paradoxe qu'il déplace toujours mais auquel il n'échappe jamais, dire pour la première fois ce qui cependant avait été déjà dit et répéter inlassablement ce qui pourtant n'avait jamais été dit (Foucault 1971: 26-27).

De este modo, puede observarse un giro en sus trabajos sobre literatura en textos publicados con posterioridad a 1970 que aquí no va a desarrollarse ${ }^{9}$ (González Blanco 2018) que conlleva también la defensa y necesidad de un nuevo discurso crítico: precisamente, la problemática de la crítica francesa que le era contemporánea y que Roland Barthes (1959: 145-148) describía en «Nuevos caminos de la crítica literaria en Francia». Por su parte, en «La folie, l'absence d'œuvre» (1964), Michel Foucault exponía que estos lenguajes secundarios no funcionarían como lenguajes «exteriores» a la literatura. La crítica forma parte en el corazón de la literatura, dice Foucault, del «vacío»

${ }^{9}$ Se ha estudiado recientemente un giro político en los trabajos que Foucault dedica a la literatura a partir de la década de los setenta en «The Politics of Literature in Michel Foucault: Veridiction, Fiction and Desire» (González Blanco 2018). 
que ella instaura dentro de su propio lenguaje. Estos textos, dice Foucault, son el movimiento necesario, pero necesariamente inacabado, dada su relación con la literatura y la naturaleza de ésta. La crítica no es escritura, del mismo modo que es posible encontrar crítica dentro de la misma literatura, según Foucault.

Esta concepción de la crítica como escritura, que se nutre del mismo lenguaje que la propia literatura o que el lenguaje del pensamiento, es el tema central de la segunda sesión de «Langage et littérature» (1964). Foucault profundizaba aquí acerca de la naturaleza del ser del lenguaje en su relación con la crítica, su «reciente cambio», y su contraste con la multiplicación del discurso de lo que llama irónicamente Foucault, «homo criticus», figura que procedería igualmente de la inauguración de la modernidad en el siglo XIX. En este estudio, Foucault afirma que los verdaderos actos de crítica hay que buscarlos en la misma literatura, en poemas de René Char o en fragmentos de Blanchot, en los textos de Ponge, en los que la crítica se convierte en una «Se podría decir que la crítica se convierte en una función del lenguaje en general, pero sin organismo ni asunto propio») (Foucault 1996: 82). Desde aquí, en un texto también de 1964, «Le Mallarmé de J.-P. Richard»: «Un libro no es importante por las cosas que remueva, sino cuando el lenguaje, a su alrededor, se desarregla, habilitando un vacío que se convierte en su lugar de residencia» (Foucault 1996: 201).

Así pues, según el autor, no es posible hacer indistinguible el discurso primero del discurso secundario. No obstante, dado que tal estatuto es histórico, encontramos ya en cada texto la posibilidad de su transformación. Y ello debido a la naturaleza doble y al ser del lenguaje, que extienden los poderes del lenguaje a todos los discursos que componen una sociedad.

\section{LA HERMENÉUTICA ONTOLÓGICA DE LA LITERATURA}

En Teoría hermenéutica y literatura (1991), J. M. Cuesta Abad señala que la hermenéutica parte de la idea de que «debajo del sentido "común" existe un sentido oculto y más profundo». Si aceptamos esta hipótesis de partida, entonces el análisis de la obra de Raymond Roussel que Michel Foucault realiza en 1963 parte de un presupuesto genuinamente hermenéutico. Cuando Raymond Roussel publicó Cómo escribí algunos de mis libros (Comment j'ai écrit certaines de mes libres) en 1935, este texto parecía perseguir como único fin aclarar de una vez por todas las claves de lectura de su propia obra. No obstante, Michel Foucault considera que la clave allí descrita no era un fin, sino antes bien un umbral, un recomienzo de la lectura que multiplica los sentidos. Y este es uno de los rasgos ya descritos de la hermenéutica foucaultiana, a saber, el reconocimiento de la naturaleza plural del texto. 
El interés de Michel Foucault por la literatura es una constante que se extendió desde los primeros años de su producción hasta sus últimas obras ${ }^{10}$, pero Raymond Roussel es la única obra dedicada exclusivamente al análisis e interpretación de una obra literaria. Su objeto, repite sucesivamente Foucault, es el de «mostrar» al lector los umbrales de la obra de Roussel. Y aquí, sin duda, este «dar a ver» está cargado de la ironía que ya contenía la propia metáfora del ojo del lector, y es, al mismo tiempo, una apelación a la idea foucaultiana de que la literatura es pensamiento en imágenes, esto es -y según se ha expuesto ya-, de que la lectura del texto literario da a ver en la imagen un «pensamiento poético», antes que un referente (mímesis) («Le Mallarmé de Jean-Pierre Richard», 1964).

Este comentario meticuloso de la obra de Roussel que partía, a su vez, de otro comentario (Comment j'ai écrit certaines de mes livres), repitiendo la estructura de mise en abyme muy habitual en la escritura del poeta y novelista, está en la base del pensamiento de Foucault sobre la literatura, adelantando ya el proyecto de una ontología de la literatura («La pensé du dehors», 1966) así como de sus reflexiones sobre literatura («Langage et literature», 1964, entre otros) y sobre análisis del texto (L'ordre du discours, 1970). Pero, sobre todo, contiene ya la asociación entre hermenéutica y ontología de la literatura que encontramos en sus obras posteriores.

El modelo de Michel de Foucault para una ontología de la literatura tenía su antecedente inmediato en su contemporáneo Maurice Blanchot (L'espace littéraire, 1955) y ambos habrían partido de una lectura crítica de la hermenéutica ontológica de Martin Heidegger. Pero, tanto en el caso de Michel Foucault como en el de Maurice Blanchot, lo que proponen no es un acceso al ser a través de la literatura, sino una ontología material en sí misma. Esto es, no se trata aquí del sentido clásico de la ontología de la literatura que se había asociado a la hermenéutica, como en los comentarios de Heidegger sobre Hölderlin, o los de Gadamer sobre Celan. Recordemos que para Martin Heidegger, fundamentalmente en los últimos años de su producción, el lenguaje en general, y particularmente la literatura, es el lugar donde el hombre accede al Ser, pues el Ser se articula lingüísticamente en la literatura. Como para Foucault, en Heidegger la comprensión se actualiza dentro de un contexto de significados no convergente (in der Welt Sein). El Dasein y el sentido son, pues, en ambos pensadores, históricos. Como explica Cuesta Abad, el ensayo de Heidegger sobre «El origen de la obra de arte» (1950) sostiene que la obra literaria es histórica (geschichlich), por cuanto en ella el ser absoluto que adviene se inviste de temporalidad y ella misma funda la historia al representar nuevamente su mundo a una humanidad determinada; pero no es «Histórica» (historisch,

${ }^{10}$ Los análisis de las tragedias de Eurípides en los años ochenta son un claro ejemplo de un interés en la última fase de su producción. 
que pertenece a la Historia) como quería el historicismo positivista del siglo XIX (Cuesta Abad 1991: 30). Y este presupuesto sería común, en parte, al planteamiento foucaultiano.

No obstante, si para Heidegger, cuando la proposición es verdadera, ello significa que descubre al ente en sí mismo, es decir, «el ser verdadera es ser descubridora $\gg^{11}$ (ibíb.: 27). El decir para Heidegger significa mostrar (el ser de las cosas), desocultación donde el ser se hace visible. Lo que se muestra y lo mostrado: signo y designado. El habla pertenece a lo que está en presencia: «La estructura del habla da lugar a la manifestación óntica de la realidad a través de los signos». De otro modo, para Foucault, si el lenguaje es capaz de acceder al Ser del mundo, es para transformarlo, pues cada lectura constituye una acción sobre el ser del mundo. Al tiempo que, dado su concepto de lenguaje, que pone de relieve la materialidad, Foucault abre así la puerta a la Otredad no representativa del lenguaje, una Otredad «inhumana».

Finalmente, como señala Humbert Dreyfus en «Being and power» (2004), existe una diferencia fundamental en las ontologías presentadas por estos dos pensadores, y es la consideración nietzscheana de que los seres se encuentran en una lucha constante, una lucha no dialéctica. Pero además, en Foucault, como los seres mismos, el lenguaje de esta ontología literaria vuelve siempre el mismo siendo otro, sin proceso dialéctico:

Now we come to the important difference between Heidegger's and Foucault's ontologies. For Heidegger, the basic way the background practices work is by gathering and so bringing things into their own. Human beings, as world disclosers, must preserve and respond to these practices. For Foucault, on the contrary, the background practices reveal, as they do in Nietzsche, a constantly shifting struggle. Thus there is no way to be receptive to them (Dreyfus 2004: 50).

En Raymond Roussel, las figuras del ser del lenguaje se perpetuaban en una lucha no dialéctica:

C'est une cosmologie du Même. Gigantesque arche de Noé (plus accueil encore) qui ne reçoit pas les couples pour que se multiplie l'espèce, mais qui apparie les choses du monde les plus étrangères pour que naisse d'elles enfin la figure de leur repos, le monstre unique, insécable de l'identité. [...] où les conjonctions les plus inattendues cherchent en vain à instaurer le règne du Même. Et par un effet d'ironie objective, c'est la répétition seule de ces tentatives désamorcées qui fait naître la forme vide, jamais assignable en une chose précise, de l'identique (Foucault 1963: 187).

La hermenéutica no sólo introduce, siguiendo a Cuesta Abad (1991: 15-16), «la genuina "exterioridad del Ser" en los estrechos límites del universo racional del hombre». El Ser convive aquí con otro ser, el ser mismo del lenguaje, su

${ }^{11}$ La cursiva es mía. 
ser material. La hermenéutica ontológica de Foucault es una hermenéutica material en tanto que el ser del lenguaje adquiere una autonomía y convive con un Ser ajeno al lenguaje.

Ontología material, porque es desde la materialidad limitada e infinita del lenguaje, desde donde Roussel desdobla el lenguaje. De manera que la hermenéutica ontológica que Foucault trabaja en la obra de Roussel estaría dentro de las propuestas para una «nueva hermenéutica literaria» de la literatura del siglo XX, siguiendo la idea de Peter Szondi (2006), como hermenéutica «opuesta a la hermenéutica filológica tradicional» y más adecuada a la literatura no imitativa (Wahnón 2008: 248). Téngase en cuenta que Roussel, según Foucault, escapa desde su propósito, desde el origen de la escritura, a cualquier intención mimética. Su escritura está cercana a la materialidad de los manieristas, que miran la obra de arte antes que la naturaleza misma. Roussel quiere mostrar los poderes del lenguaje, dominarlos con sus procedimientos que no hacen otra cosa que evidenciar estos poderes.

Este concepto de lenguaje sería común a la obra de los dos autores franceses. Para Foucault, el lenguaje es capaz de hablar, al mismo tiempo, del mundo y de sí mismo; dada su naturaleza dual, que le permite significar, referirse a un exterior (mundo, referente), incidiendo sobre él (voluntad de poder, capacidad performativa del lenguaje) y no dejar de significarse, de hablar sobre sí mismo (materialidad). Y, del mismo modo, expone Foucault, para Roussel el ser móvil del acontecimiento es el que recorre el lenguaje y su «ser». De ahí el protagonismo del verbo ser:

Et grâce au pouvoir merveilleux du verbe «être» le langage de la Vue se maintient au niveau d'un épiderme descriptif, tout bariolé de qualités et d'épithètes, mais aussi proche qu'il se peut de l'être qui à travers lui se rend sensible (Foucault 1963: 174).

Foucault asimila así en su concepto de lenguaje la reflexión fenomenológica, la analista y la formalista. Y ello es posible precisamente desde una ruptura con el pensamiento lógico clásico, que partía con Parménides y era formulado por Aristóteles, con el principio de identidad, identificando lógica y metafísica.

Hay un principio, en las cosas que son, acerca del cual no es posible caer en error, sino que siempre se hace necesariamente lo contrario, o sea, estar en la verdad: que «no es posible que lo mismo sea y no sea, a un mismo tiempo», e igualmente en el caso de los otros predicados que se oponen entre sí de este modo (Aristóteles 2000: 1061b 35).

Michel Foucault estaría realizando así una crítica del pensamiento lógico-racional en el que prevalece una concepción del ser idéntico a sí mismo («A es A, esto es, cada A es él mismo lo mismo» Heidegger 1988: 63), que llegaba 
a identificar identidad y verdad, de modo que «verdadero es lo que no encierra contradicción y, consiguientemente, es idéntico a sí mismo» (Gabilondo 2001: 72). En contraposición a esta lógica de la identidad, Foucault opone un ser del lenguaje «inhumano», sometido al azar de su materialidad, plural. Pues, como explica Sara Koffman, el principio de identidad es antes un principio «humano, demasiado humano» que lógico u ontológico, y la incapacidad del hombre de afirmar y negar simultáneamente una misma cosa (Kofman 1979: 144-145).

Esta apertura ontológica del ser del lenguaje, siguiendo el movimiento de ida y vuelta de un ser sobre otro (ser doble del lenguaje), repercutiría sobre el Ser genuino. En Platón importa la distancia entre la origen ontológico del lenguaje (Crátilo) y la sospecha sobre los poderes del lenguaje literario, capaz de crear una «ontología fantástica» (Foucault 1963: 50), inexistente, en tanto que presenta modelos de ser no concordes con los asumidos, según las jerarquías ontológico-sociales que su filosofía expone. Así, recuérdese a Ión, el hermeneuta $^{12}$ de los textos homéricos, lector ávido que expone las consecuencias ontológicas de la lectura. O como Alcibíades, Ión padece lo que bien podríamos denominar «el síndrome del Quijote», esto es, la identificación de texto y mundo $^{13}$. El lector fascinado por el texto se apropia de él de tal modo que de éste extrae una experiencia. Por ello, Ión se pretende auriga, pescador o adivino (Platón 2000: 536e/537a). Los intérpretes de los dioses son los que crean un mundo independiente. Es precisamente este poder del lenguaje de dar lugar a seres inéditos, el que reclama Foucault para la escritura. Y desde donde Foucault afirma la experiencia transformadora que es posible alcanzar desde la lectura.

Partiendo de la lectura que realiza del escritor francés Raymond Roussel y de la interpretación que este hace de su propia escritura, Foucault desarrolla una ontología de la literatura cuya potencia se expresa en el ser del lenguaje mismo. Como si la configuración (doble) que impone el lenguaje se convirtiera en el ser espontáneo de los hombres y las cosas; máquinas maravillosas que fabrican seres: este es el poder ontológico de este lenguaje ahogado (Foucault 1963: 39).

Esto es, el poder del lenguaje de dar lugar a seres inéditos y ello a través de dos movimientos inherentes al lenguaje: un movimiento semejante al de la metáfora misma, dando lugar a la conjugación de seres distantes entre sí. Y otro de desdoblamiento de las palabras, en lo que, según Foucault, parte de un equívoco, una paradoja, que hace posible que los cuentos de Roussel sean leídos en los dos sentidos. Este mecanismo doble es el que se encuentra en la

${ }^{12}$ Herméneuitai eran tanto los visionarios, los portavoces de oráculos como los poetas: iluminados, visionarios, poetas.

${ }^{13}$ Para un desarrollo de esta cuestión véase: «Cervantes lector de Platón: parodia y tropelía» (González Blanco 2006) y «Razón y Sinrazón en "El licenciado Vidriera", "El casamiento engañoso" y "El coloquio de los perros» (González Blanco 2013). 
base de estos cuentos de Roussel (ibíd.: 92). De este modo, los seres que surgen de sus historias son seres múltiples y contradictorios que surgen de los enunciados no dialécticos («no fabricados»), sino que conviven en el texto bajo la forma de la paradoja. Por tanto, el procedimiento utilizado por Roussel pone de relieve un hecho fundamental: de un hecho formal, esto es, de la pobreza y riqueza del lenguaje a un mismo tiempo, surgen seres de naturaleza dual (ibíd.: 26). Y, consecuentemente, la lógica del lenguaje literario es la lógica del doble.

Así, el enigma que Roussel parece desvelar quedaría imbricado de este modo aún más, de manera que ya no es posible llegar a una única lectura. La revelación resulta ser una clave para el enigma que ya no se puede resolver, como en la paradoja: «la imposibilidad de decidir» (10). Foucault nos muestra que Comment j'ai..., que se presenta como una clave, no deja de ser una obra más del autor. La llave que sirve, pues, a la vez, para encadenar y liberar, como el lenguaje mismo:

La promesse de la clef, dès la formulation qui la livre, esquive ce qu'elle promet ou plutôt le renvoie au-delà de ce qu'elle-même peut livrer, à une interrogation où tout le langage de Roussel se trouve pris. Etrange pouvoir de ce texte destiné à «expliquer» (Foucault 1963: 13).

La hermenéutica foucaultiana demuestra incesantemente, a lo largo de toda su producción, que un texto es susceptible de mostrar una verdad que previamente había sido callada (Histoire de la folie, Histoire de la sexualité). Ello nos permite conectar esta primera etapa de la producción del francés, con aquellas ideas que desarrolla en la década de los ochenta hasta su muerte. En contraposición a la aletheia, que es el ser-verdad del logos, Foucault (2004) asume para su hermenéutica en sus conferencias de Berkeley el concepto clásico de la parresía como un «decirlo-todo». La aletheia es el mostrar «claramente» el ser, no ocultarlo, que en la retórica de Aristóteles se relacionaba con un mostrar la verdad a todos de modo claro, evitando los enigmas, esto es, basado en el «sentido común», el sentido que más claramente se muestra a la mayoría. Por su parte, el decirlo-todo de la parresía se relaciona precisamente con decir lo contrario de lo que la mayoría opina, ir en contra de la opinión, es un decir propio de la crítica que muestra una verdad «difícil». Y en Foucault está directamente relacionado con el ser doble del lenguaje, la paradoja y el enigma.

Le langage est cet interstice par lequel l'être et son double sont unis et séparés ; il est parent de cette ombre cachée qui fait voir les choses en cachant leur être. Il est toujours plus o moins un rébus (Foucault 1963: 154).

De este modo, cuando Foucault nos advierte de que el procedimiento expuesto por Roussel nos da la clave y al mismo tiempo redobla la obra misma de sentido, nos advierte de que ha de ser buscado otro sentido que no 
es el evidente, el habitual, que la hermenéutica se hace necesaria. Se abre así un «espacio de incertidumbre sin descanso» propuesto desde la «imposibilidad de decidir si hay un secreto, ninguno o varios, y cuáles son» (Foucault 1963: 19-20). Y ello porque la identidad de las palabras es una experiencia de doble vertiente: se revela en la palabra el lugar de un encuentro imprevisto entre los seres del mundo más alejados, «es la distancia abolida, el punto de entrechoque de los seres, la diferencia recogida sobre sí misma en una forma única, dual, ambigua, minotaurina» (ibíd.: 26). Puede afirmarse, de este modo, que existe ya en el lenguaje un poder metafórico que le es inherente, pero sobre todo, que existe un ser paradójico que le otorga al lenguaje su potencialidad doble y, en definitiva, su riqueza contenida en una materialidad finita e incluso reducida (como la biblioteca borgiana). Pues, en la proposición metafórica como en la paradoja, se acercan dos realidades completamente apartadas entre sí. Ahora bien, a la metáfora se le ha otorgado una capacidad epistemológica (la de conocer a partir de las semejanzas), mientras que la paradoja ha sido criticada por sus consecuencia lógicas (crítica del irracionalismo: literatura y locura) y ontológicas (ser al mismo tiempo A y no A). Las máquinas de Roussel asumen, según Foucault, estas dos funciones fundamentales: unir dos realidades distantes, superponiéndolas, en una yuxtaposición no dialéctica a modo de la metáfora (como la lombriz-músico, el gallo-escritor, la miga de pan y el mármol), o como la paradoja, uniendo incompatibles (el hilo de agua y el hilo de tela, el azar y la regla, la incapacidad y el virtuosismo) o uniendo realidades sin relación posible de tamaño (escenas compuestas en el interior de granos de uva embrionarios; mecanismos musicales ocultos en el espesor de unas barajas de tarot).

Por ello, dada la autoconciencia de su escritura, que se sitúa en las antípodas de la escritura automática, es en la literatura de Roussel donde mejor se puede apreciar este ser doble del lenguaje. La escritura de Roussel es capaz de mostrar, a través de los diversos procedimientos, «un desdoblamiento del lenguaje que, a partir de un núcleo simple, se aparta de sí mismo y hace nacer sin cesar otras figuras» (Foucault 1963: 27). Roussel mostraría, de este modo, un movimiento inherente al lenguaje con consecuencias ontológicas: el vínculo significante-significado puede «metamorfosearse», multiplicando las posibilidades de cada palabra, es decir, sus «sentidos» (27).

En definitiva, para Foucault como para Nietzsche o Dumarsais, el lenguaje tiene un origen tropológico con consecuencias ontológicas que, según él, nada tienen que ver con las «figuras de estilo», esto es, con decir lo mismo de otro modo. Al contrario «todo el lenguaje de Roussel, estilo invertido, procura decir subrepticiamente dos cosas con las mismas palabras». Precisamente en este espacio tropológico es donde se sitúa la escritura de Roussel:

C'est de cet espace de déplacement que naissent toutes les figures de la rhétorique (le «tour» et le «détour», comme dit Dumarsais); catachrèse, métonymie, méta- 
lepse, synecdoque, antonomase, litote, métaphore, hypallage et bien d'autres hiéroglyphes dessinés par la rotation des mots dans le volume du langage. L'expérience de Roussel se situe dans ce qu'on pourrait appeler «l'espace tropologique» du vocabulaire (Foucault 1963: 24).

En este umbral donde el lenguaje dice el mundo y su Otro, Roussel encuentra el espacio de la escritura, lo neutro según Blanchot, o la capacidad creadora de un lenguaje que tiene en su ser potencia creadora indominable. Es la «dinastía de lo improbable»:

Il y sent, plus que les semi-libertés de l'expression, une vacance absolute de l'être qu'il faut investir, maîtriser et combler par l'invention pure: c'est ce qu'il appelle par opposition à la réalité, la «conception» («chez moi, l'imagination est tout»); il ne veut pas doubler le réel d'un autre monde, mais dans les redoublements spontanés du langage, découvrir un espace insoupçonné et le recouvrir de choses encore jamais dites (ibíd.: 25).

Proyecto que Foucault compartiría con Roussel, pues para Foucault la literatura, con su poder de encontrar «formas inéditas de ser» ofrece modos de liberación de los modelos de normalización que la sociedad moderna ha impuesto. Por tanto, en esta primera etapa de la producción de Foucault, la literatura sería antes que mímesis la vía de acceso a lo que aún no existe, lo que podría ser. Frente a las formas normalizadas de la subjetividad, la literatura ofrece imágenes que desafían lo racional: una apertura a un proyecto múltiple, heterotópico. Se trata, en definitiva, del poder creador del lenguaje y de su capacidad de reinventar la realidad, como realidad lingüística.

Por ello, tras la pregunta por el ser del lenguaje anida un miedo mayor, ¿nos es el lenguaje totalmente ajeno? ¿domina el arbitrio frente al querer-decir? La respuesta de Foucault es, cómo no, doble: sí y no. El lenguaje se desvincula de su modelo a imitar, el mundo, pero sólo para volver siendo su doble y recubrirlo, e incidir sobre él. El lenguaje gana independencia y autonomía en su materialidad, pero es precisamente a través de ella desde donde el lenguaje lo-dice-todo, incluso lo que no quiere ser enunciado. El lenguaje es humano e inhumano. Por ello, porque no podemos dominar por completo sus poderes, porque no nos pertenece, el lenguaje dice más allá y crea él mismo modelos de realidad, seres inéditos. Este es el poder del lenguaje, que se dice a sí mismo, al mundo y en este gesto doble lo transforma.

La implicación del lenguaje y el ser nos descubre que ciertas alianzas trazadas entre las cosas no se realizan a partir de una semejanza referencial, sino por contigüidad formal. Las metáforas no alumbran una ontología, sino que son fruto de una ontología material de las palabras con consecuencias ontológicas: éste es el poder del lenguaje sobre el mundo. De este modo, Foucault recupera una problemática que se había escindido en el siglo XVI. En Les mots et les choses (1966), Foucault considera que el saber en el siglo XX, como en el 
siglo XVI, es un saber interpretativo. Es decir, «lo propio del saber no es ni ver ni demostrar, sino interpretar». El comentario es el género de estos siglos, de tal modo que:

Commentaire de l'Écriture, commentaire des Anciens, commentaire ce qu'ont rapporté les voyageurs, commentaire des légendes et des fables: on ne demande pas à chacun de ces discours qu'on interprète son droit à énoncer une vérité; on ne requiert de lui que la possibilité de parler sur lui. Le langage a en lui-même son principe intérieur de prolifération (Foucault 1966: 55).

Según Foucault, hasta el siglo XVI el lenguaje no era un sistema arbitrario, sino que formaba parte del mundo «porque las cosas mismas ocultan y manifiestan su enigma como un lenguaje y porque las palabras se proponen a los hombres como cosas que hay que descifrar». El mundo se concibe como la gran metáfora del libro que se lee para conocer la naturaleza. El lenguaje del siglo XVI, entendido como una experiencia cultural global, dice Foucault, se sitúa en este intersticio entre el primer Texto y el infinito de la Interpretación. Existe un principio de proliferación de la interpretación: pues se habla a partir de una escritura que forma parte del mundo, y cada uno de sus signos se convierte a su vez en escritura para nuevos discursos, «pero cada discurso se dirige a esta escritura primigenia cuyo retorno promete y desplaza al mismo tiempo» (Foucault 1966: 49).

En definitiva, para Michel Foucault, la experiencia del lenguaje pertenece a la misma red arqueológica que el conocimiento de las cosas. Conocer las cosas es revelar el sistema de semejanzas que las hace ser próximas y solidarias unas con otras. Este ser del lenguaje que había llegado hasta el siglo XVI, dice Foucault, «no existe ya en nuestro saber» pero sí está presente en la literatura. Según Foucault, en cierto sentido puede decirse que la literatura, tal como se constituyó y designó en el umbral de la época moderna, manifiesta la reaparición, allí donde no se la esperaba, «del ser vivo del lenguaje» (ibíd.: 50). El arte del lenguaje era:

\footnotetext{
Une manière de «faire signe», à la fois de signifier quelque chose et de disposer, autour de cette chose, des signes: un art donc de nommer et puis, par un redoublement à la fois démonstratif et décoratif, de capter ce nom, de l'enfermer et de le celer, de le désigner à son tour par d'autres noms qui en étaient la présence différée, le signe second, la figure, l'apparat rhétorique (Foucault 1966: 58).
}

Ahora bien, para Foucault, a lo largo del siglo XIX hasta llegar a nosotros, de Hölderlin a Mallarmé y Antonin Artaud, la literatura recupera ese ser en bruto olvidado desde el siglo XVI y es por lo que no puede ser pensada desde una epistemología, sino desde una hermenéutica ontológica. Según el autor, la literatura moderna es lo que compensa el «funcionamiento significativo del lenguaje», pero no como una teoría de la significación. Sino que, desde el siglo 
XVI, la literatura hace posible aparecer de nuevo una ontología del lenguaje, antes que una teoría de la significación. De ahí, afirma Foucault, la necesidad de «pensar la literatura» (Foucault 1966: 51).

Foucault propone, de este modo, una hermenéutica ontológica que recupere el ser del lenguaje, aquel que es capaz, en su doble movimiento, de ir de las palabras a las cosas y viceversa. La lectura es así la vía de actualización de los poderes del lenguaje. Por ello es tan importante en la obra de Foucault la labor del archivista, del arqueólogo, del filólogo y del hermeneuta: es necesario leer para hacer factibles los poderes del lenguaje que transforma una realidad histórica concreta.

\section{Conclusiones}

Podemos concluir, por una parte, que la hermenéutica ontológica y material de Michel Foucault se enfrenta a la hermenéutica monista que pretende la existencia de una única verdad interpretativa. Esta hermenéutica atiende a las distintas lecturas que cada momento histórico hace posible y, por tanto, no asegura un programa total de interpretación. Así pues, que cada lectura, el lugar elegido para emprender la hermeneusis, es una ética lo entendió mejor que nadie este autor. Sus obras son siempre una aproximación, una posible lectura levantada siempre desde la genealogía del problema propuesto. Hermenéutica plural, las lecturas foucaultianas son igualmente incompatibles con una hermenéutica progresiva de acumulación de lecturas que suman una verdad final.

Desde aquí es también desde donde caracteriza Foucault la tarea del intelectual y la del lector, como «el no hablar por otros», estar a la escucha de los grupos polifónicos de los textos. Por ello, la filosofía de Foucault es antes experimentación que interpretación al uso, como lo era para Gilles Deleuze la filosofía en ¿Qué es la filosofía? (1999). Precisamente Gilles Deleuze, en una entrevista que dedica a su contemporáneo titulada «Michel Foucault», dice que la filosofía de Foucault se opuso a la interpretación al uso, no interpretar jamás, sino experimentar (Deleuze 1990: 133-189).

La hermenéutica de Foucault es una hermenéutica experimentadora, hermenéutica arqueológica y genealógica. Y ello porque la naturaleza plural del lenguaje posibilita que las interpretaciones sean múltiples y que un mismo texto sea susceptible de ser interpretado en direcciones diferentes dependiendo del momento histórico. Es decir, las interpretaciones están determinadas por el ahí del lector, el momento histórico (el horizonte de interpretaciones).

En consecuencia, el ser en Foucault es un ser-en-el-mundo que está indisociablemente unido a un ser-en-el-lenguaje: la potencialidad del ser que actúa en el lenguaje y por el lenguaje. Es este ser doble y su potencia ilimitada, los que hacen posible una transformación del mundo, espacio habilitado para la expresión del ser lingüístico. El ser del mundo, como tal, es sólo un proyecto, una hete- 
rotopía, en tanto que nunca está dado por completo. No se trata de una incapacidad nihilista sino, al contrario, de una capacidad inherente al ser lingüístico. La capacidad paradójica y perlocutiva del lenguaje y del ser irremediablemente lingüístico hacen del mundo como materialidad pura una proyección metamórfica. Los documentos, entes materiales, recogen las características del lenguaje doble y transformador, al tiempo que, como interpretable-legible, está abierto a las actuaciones y es espacio de actuación: el lenguaje alumbra la realidad en el decirse. La hermenéutica de Foucault no evidencia un ser del mundo, sino que transforma el ser-mundo. El ser-mundo sólo admite en su esencia la apertura radical de una hermenéutica que actúa, que no da-a-ver. La hermenéutica actúa sobre los textos y el mundo. Es una hermenéutica, por tanto, de la transformación y de la construcción. Y podría afirmarse que la función predominante de la literatura sería la ontolingüística, esto es, la del ser diciéndose a sí mismo. Pero esta hermenéutica presenta también un espacio común para el sujeto y la escritura, pues ambos comparten un espacio ontológico que alumbra, en el azar y el dinamismo del lenguaje, formas inéditas de ser.

Dos claves, pues, guían la hermenéutica foucaultiana: interpretar es actuar y la pregunta por el sentido es la pregunta por el ser. En este sentido, dos perspectivas que habitualmente se han venido confrontando conviven en este pensamiento. Una, la del diálogo, centrada en la herencia, en la recuperación de textos del pasado, pues para Foucault es necesario hacerse entender, para que la herencia de los textos no se pierda. Sin embargo, la lectura tiene también un componente creativo: nuevas formas de lectura, nuevas formas de comprender lo que ya se visto, los mismos textos. La hermenéutica que practica Foucault en sus textos es la recuperación de una memoria que nunca ha sido escrita (Benjamin) y es, al mismo tiempo, como nos demuestra su lectura de Raymond Roussel, una hermenéutica de la voluntad: la lectura como creación de formas inéditas de pensar, de ser. La interpretación que descubre la verdad como parresía, es decir, que dice lo contrario al sentido común, al sentido reconocido, habitual, que busca, tras el sentido común, aquel que había quedado sumergido, el sentido crítico. Para Foucault, en consecuencia, la hermenéutica ontológica crítica es desde donde se participa de la construcción de una realidad y de una comunidad histórica, con consecuencias sobre las formulación de nuevos proyectos de subjetividades: «Las cosas y el lenguaje forman lo que nosotros mismos somos» (Foucault 1963: 188). Porque el lenguaje de la literatura comunica, dice Foucault, con la razón de nuestro mundo. Lo que la literatura del absurdo, como la de Roussel, nos enseña es que «lo que falla no es el sentido sino los signos, que sin embargo sólo significan por esta carencia» (Foucault 1963: 188).

Espacio lingüístico, que es el nuestro, donde encontramos las obras de Roussel. Puede definirse entonces a Roussel como el inventor de un lenguaje que sólo se dice a sí mismo, de un lenguaje absolutamente simple en su ser redoblado, de un lenguaje del lenguaje, que encierra su propio sol en su flaqueza soberana y central (Foucault 1963: 188). 


\section{BIBLIOGRAFÍA CITADA}

Aristóteles (2000). Metafisica. Madrid: Gredos.

Asensi, Manuel (2003). Historia de la teoría de la literatura, vol. II. Valencia: Tirant lo Blanc.

Barthes, Roland (1959). «Nuevos caminos de la crítica literaria en Francia», en Variaciones sobre la literatura. Barcelona: Paidós, pp. 145-148.

Barthes, Roland (1966). Critique et vérité. Paris: Seuil [trad. Crítica y verdad, Siglo XXI: Madrid].

Benjamin, Walter (1923). «La tarea del traductor», en Angelus Novus. Barcelona: Edhasa, pp. 127-143.

Cuesta Abad, José Manuel (1991). Teoría hermenéutica y literatura. Madrid: Visor.

Deleuze, Gilles (1990). «Michel Foucault», en: Conversaciones. Valencia: Pretextos. pp. 133-189.

Dreyfus, Humbert (2004). «Being and Power. (Revisited)». Accesible en: <https://goldberg. berkeley.edu/courses/S06/IEOR-QE-S06/being.power_hubert.dreyfus.pdf> [Consultado el 01/02/2019]

Foucault, Michel (1963). Raymond Roussel. Paris: Folio.

Foucault, Michel (1966). Les mots et les choses. Une archéologie des sciences humaines. Paris: Gallimard.

Foucault, Michel (1971). L'ordre du discours. Leçon inaugurale au Collège de France prononcée le 2 décembre 1970. Paris: Gallimard.

Foucault, Michel (2004) [1983]. Discurso y verdad en la antigua Grecia, Barcelona: Paidós.

Foucault, Michel (1996). De lenguaje y literatura. Barcelona: Paidós.

Foucault, Michel (2001). Dits et écrits I. Paris: Quarto Gallimard.

Foucault, Michel (2013). La grande étrangère. À propos de littérature. Paris: EHESS.

Gabilondo, Ángel (2001). La vuelta del otro. Diferencia, identidad, alteridad. Madrid: Trotta.

González Blanco, Azucena (2006). «Cervantes lector de Platón: parodia y tropelía», $L L$ Journal. I, 2, pp. 9-30.

González Blanco, Azucena (2007). «Thomas l'obscur, o hacia una nueva experiencia de lectura», Sociocriticism. XXII, 1 y 2, pp. 275-293.

González Blanco, Azucena (2013). «Razón y Sinrazón en "El licenciado Vidriera", "El casamiento engañoso" y "El coloquio de los perros"», Confluencia. Revista Hispánica de Literatura y Cultura. 28 (2), pp. 180-195.

González Blanco, Azucena (2018). «The Politics of Literature in Michel Foucault: Veridiction, Fiction and Desire», CLCWEB. Comparative literature and culture. 20 (4), pp. 1-8. https://doi.org/10.7771/1481-4374.3353

Hegel, Georg Wilhelm Friedrich (2004) [1807].Fenomenología del Espiritu. Madrid: Fondo de Cultura Económica.

Heidegger, Martin (1988). Identidad y diferencia (ed. bilingüe). Barcelona: Anthropos.

Jay, Martin (2008) [2003]. Ojos abatidos. La denigración de la visión en el pensamiento francés del siglo $X X$, Madrid: Akal.

Klawitter, Arne (2003). Die «fiebernde Bibliothek». Foucaults Sprachontologie und seine diskursanalytische konzeption moderne Literatur. Heidelberg: Synchron.

Kofman, Sarah (1979). Nietzsche et la scène philosophique. Paris: Union Générale d'Éditions.

Micieli, Cristina (2003). Foucault y la fenomenología. Kant, Husserl, Merleau-Ponty. Buenos Aires: Biblos.

Nietzsche, Friedrich (1994). Sobre verdad y mentira en sentido extramoral. Madrid: Tecnos. 
Peretti, Cristina de (1994). «Foucault: The Twofold Games of Language», en Ricardo Miguel-Alfonso y Sylvia Caporale-Bizzini (eds.), Reconstructing Foucault: Essays in the wake of the 80's. Amsterdam: Rodopi.

Platón (ed. 2000). Diálogos I. Madrid: Gredos.

Sagnol, Marc (1983). «La Methode Archeologique de Walter Benjamin», Les Temps Modernes. 444, pp. 143-165.

Szondi, Peter (2006). Introducción a la hermenéutica literaria. Madrid: Abada.

Wahnón Bensusan, Sultana (2008). Teoría de la literatura y de la interpretación literaria. Ensayos y reflexiones. Vigo: Academia del Hispanismo.

Fecha de recepción: 18 de julio de 2016.

Fecha de aceptación: 22 de febrero de 2017. 